\title{
Two-diode model for parameters extraction of photovoltaic module under temperature variation
}

\author{
Nahla M. Shannan ${ }^{1}$, Nor Zaihar Yahaya ${ }^{1 a)}$, Balbir Singha ${ }^{1}$, \\ Zainal Salam $^{2}$, and Khalid Y. Ahmed ${ }^{1}$ \\ ${ }^{1}$ Universiti Teknologi PETRONAS, Electrical \& Electronics Engineering \\ Department, 32610 Bandar Seri Iskandar, Perak, Malaysia \\ ${ }^{2}$ Universiti Teknologi Malaysia, Center of Electrical Energy Systems, g, Faculty of \\ Electrical Engineering, 81310 UTM Johor Bahru, Malaysia
}

a)norzaihar_yahaya@petronas.com.my

\begin{abstract}
This paper study the effect of redistributing the series resistance in the two-diode model of the PV module according to its physical components, considering the relation of each component to temperature variation. The proposed model divide the series resistance into two materials: metal and semiconductor, constructing the mathematical model for the overall model. The model is found to improve the accuracy in calculating the maximum power point with temperature variation, which contribute to the job of PV power converter designers and circuit simulator developers.
\end{abstract}

Keywords: series resistance, parameters extraction, PV module, two-diode model

Classification: Electron devices, circuits, and systems

\section{References}

[1] K. Ishaque and Z. Salam: Sol. Energy 85 (2011) 2349. DOI:10.1016/j.solener. 2011.06.025

[2] D. Pysch, A. Mette and S. W. Glunz: Sol. Energy Mater. Sol. Cells 91 (2007) 1698. DOI:10.1016/j.solmat.2007.05.026

[3] C. S. Solanki: Solar Photovoltaics: Fundamentals, Technologies, and Applications (PHI Learning Private Limited, Delhi, 2013) 2nd ed.

[4] X. Weidong, W. G. Dunford and A. Capel: Power Electronics Specialists Conference, 2004. PESC 04. 2004 IEEE 35th Annual 3 (2004) 1950. DOI:10. 1109/PESC.2004.1355416

[5] S. M. Sze and K. K. Ng: Physics of Semiconductor Devices (John Wiley \& Sons, New York, 2007).

[6] A. N. Celik and N. Acikgoz: Appl. Energy 84 (2007) 1. DOI:10.1016/j. apenergy.2006.04.007

[7] I. Altas and A. Sharaf: International Conference on Clean Electrical Power, 2007. ICCEP'07 (2007) 341. DOI:10.1109/ICCEP.2007.384234

[8] J. Ding, X. Cheng and T. Fu: Vacuum 77 (2005) 163. DOI:10.1016/j.vacuum. 2004.08.019

[9] W. De Soto, S. A. Klein and W. A. Beckman: Sol. Energy 80 (2006) 78. 
DOI:10.1016/j.solener.2005.06.010

[10] M. Villalva and J. Gazoli: IEEE Transactions on Power Electronics 24 (2009). DOI:10.1109/TPEL.2009.2013862

[11] K. Ishaque, Z. Salam and H. Taheri: Sol. Energy Mater. Sol. Cells 95 (2011) 586. DOI:10.1016/j.solmat.2010.09.023

[12] R. Chenni, M. Makhlouf, T. Kerbache and A. Bouzid: Energy 32 (2007) 1724. DOI:10.1016/j.energy.2006.12.006

\section{Introduction}

One of the elements in the PV cell that caught the attention of the power system engineer is the series resistance, because of its role in having a proper evaluation of the current-voltage characteristics, cell matching, and the prediction of the PV cell output under different illumination and temperature conditions. In practice, the series resistance has much more effect than the parallel resistance, as an increase in the value of the series resistance from $0 \Omega$ to $5 \Omega$ reduces the available power to less than $30 \%$ of the optimum power at $0 \Omega$ [1]. The rapid development in the field of solar cell production implies an increase in the area and hence the finger length of the industrial solar cell, which leads to an increase in the series resistance as well as the power loss due to the series resistance [2]. On the other hand, the daily exposure of the PV module to sunlight and its thermal effect results in a gradual increase in series resistance $R_{S}$ of the module. This increase in the series resistance $R_{S}$ will results in a decrease in both of the maximum output voltage $V_{m}$, the maximum output current $I_{m}$, and hence the maximum output power of the solar cell. Any further increase on the series resistance will even results in a decrease in the short circuit current $I_{S C}$, as shown in Fig. 1-a. On the other hand, the value of the maximum output power $P_{\max }$, of the PV module, has an inverse relationship with the value of its series resistance, which in terms causes a reduction in fill factor $\left(F F=P_{m} / I_{S C} V_{O C}\right)$ and the efficiency $\left(\eta=P_{m} / P_{\text {in }}=F F I_{S C} V_{O C} / P_{i n}\right)$ of the PV module as shown in Fig. 1-b, Fig. 1-c and as shown in Table I. The series resistance of the solar cell represents a combination of resistance of various parts of the PV cell such as, the base resistance, emitter resistance, metal contact resistance, and metal semiconductor interface or contact resistance [3], which are mainly a semiconductor material and a metal/conductor material. Solid materials are usually classified as metals, semiconductors, or insulators. Generally, metals are the best in conducting electricity, unlike the insulators. On the other hand, semiconductor materials lies between the metals and insulators in conducting electricity, with a higher resistance than that of the metal. However, the resistance variation according to temperature distinguishes a metal from a semiconductor, as the semiconductor resistance is normally decreases when the temperature increase, while the metal resistance increases with the temperature increment. That is because of the fixed number of charge carriers in a metal, while the thermal excitation across the energy gab in a semiconductor material increases the number of carriers, in addition to the carriers added by the doping process, which implies a decrease of the semiconductor resistance [1]. Since the PV cell series resistance is actually a mixture of a metal and a semiconductor resistance [3], which exposed to temper- 
ature variation. Hence, the effect of temperature variation on the various components of the series resistance should be considered.

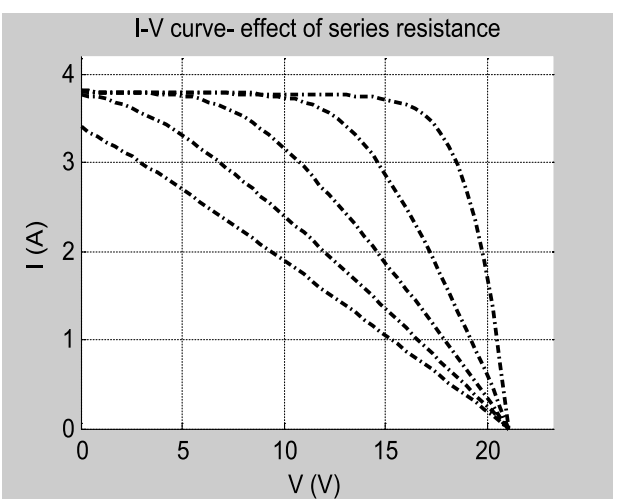

(a)

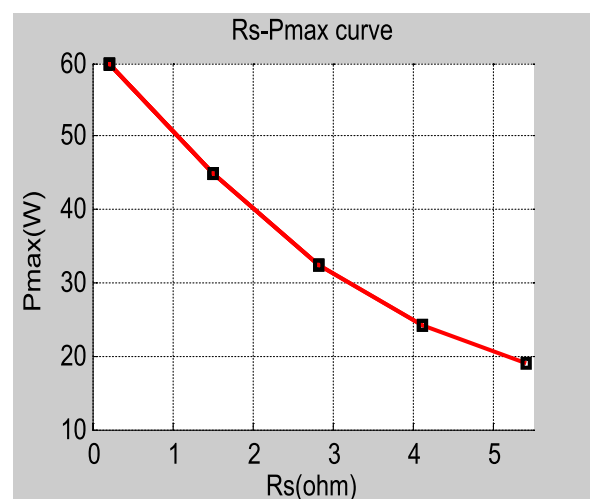

(b)

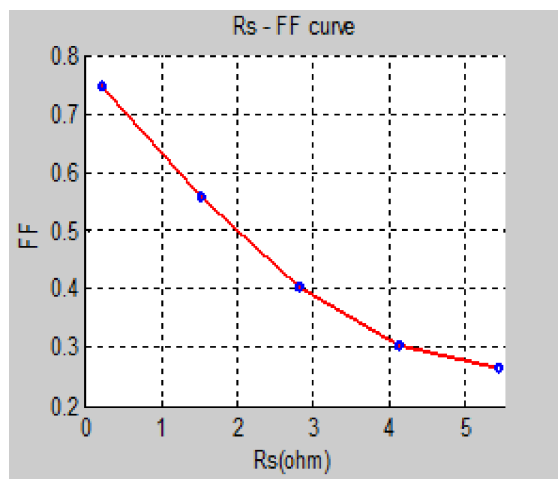

(c)

Fig. 1. Series resistance $R_{S}$ effect on the output power and fill factor of the PV module (a) effect of the increment of the $R_{S}$ value on the I-V curve (b) the relation between the $R_{S}$ value and the output power (c) the effect of $R_{S}$ on the fill factor of the PV module

Table I.

\begin{tabular}{|c|c|c|c|c|c|}
\hline \multirow{2}{*}{$R_{S}(\Omega)$} & $I_{S C}(\mathrm{~A})$ & \multirow{2}{*}{$P_{\max }(\mathrm{W})$} & $F F$ & \multicolumn{2}{|c|}{$(\%)$ loss in } \\
\cline { 5 - 6 } & & & & $P_{\max }$ & $F F$ \\
\hline 0.217 & 3.800 & 59.787 & 0.7456 & - & - \\
\hline 1.519 & 3.790 & 44.79 & 0.558 & 25.08 & 25.16 \\
\hline 2.821 & 3.790 & 32.41 & 0.404 & 46.8 & 45.82 \\
\hline 4.123 & 3.760 & 24.167 & 0.304 & 59.28 & 59.23 \\
\hline 5.425 & 3.396 & 19.014 & 0.265 & 59.34 & 64.46 \\
\hline
\end{tabular}

In this work the series losses occurred by the series resistance is redistributed across the two-diode model, considering the series losses occurred due to the semiconductor material first followed by the rest of the series losses due to metal material. The proposed model introduces an additional series resistance $R_{d}$ that represent the equivalent semiconductor part of the series resistance (the base resistance and emitter resistance) of the two-diode model, as the first series loss inside the PV cell, followed by the remaining series losses and parallel losses. 


\section{Proposed model}

Depending on the operating point, the practical PV module may be influenced by the series resistance $R_{S}$ or parallel resistance $R_{P}$. The influence of $R_{S}$ becomes stronger on the direction to the open circuit condition, while $R_{p}$ shows a strong influence in the direction to the short circuit condition. Some authors $[4,5,6,7]$ neglect $R_{p}$ to simplify the model, as it has a high value. Simultaneously, other authors neglect $R_{s}$ because of its low value. Actually, it is difficult to determine the light generated current $I_{p v}$ without considering the influence of $R_{S}$ and $R_{p}$, as the $I-V$ characteristics of the $\mathrm{PV}$ module depends on its internal characteristics $R_{s}$ and $R_{p}$. Hence in this work the different elements constructing the series resistance and their relation to temperature variation is studied using the two-diode model shown in Fig. 2.

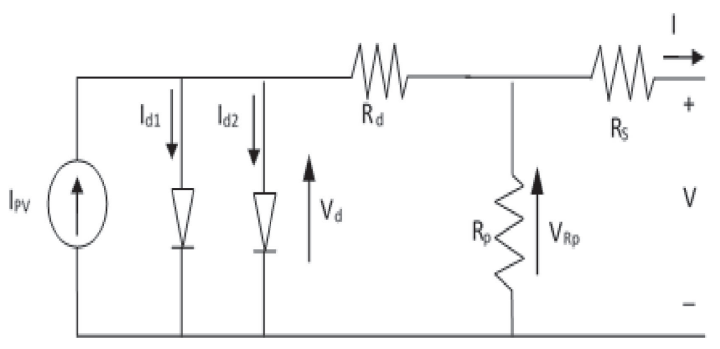

Fig. 2. Proposed two-diode model

The conductor type resistance is one of three types of thermal sensitive resistances [8], which is given by:

$$
R s=R_{o}(1+\alpha T)
$$

Where $\alpha$ is the conductor temperature coefficient, and $R_{o}$ is the condition resistance. When fitting Eq. (1) to experimental data collected from [8], with an assumption of almost equal values of semiconductor material and conductor material at STC, taking the temperature difference from the temperature at STC, instead of the instantaneous temperature. It is found that the calculated value for this resistance coincide precisely with the experimental values for temperature values more than $20^{\circ} \mathrm{C}$, at which high output power is produced, but this condition $\left(\mathrm{T}=20^{\circ} \mathrm{C}\right)$ rarely happens in actual operation [9], as shown in Fig. 3-a. The precision of this type of thermal sensitive resistance is compared to [8] including lower value of temperature $\left(\mathrm{T}=20^{\circ} \mathrm{C}\right)$, where it lower the sum of squared devotion to almost half the value obtained by [8], as shown in Fig. 3-b and Fig. 3-c, respectively. Hence, this resistance equation can represent the relation of series resistance with temperature increments for values of temperature more than its value at STC. As at STC there is no more free electrons produced in the semiconductor material due to temperature increment, implying no change in the semiconductor material resistance as shown in Fig. 3-a. 


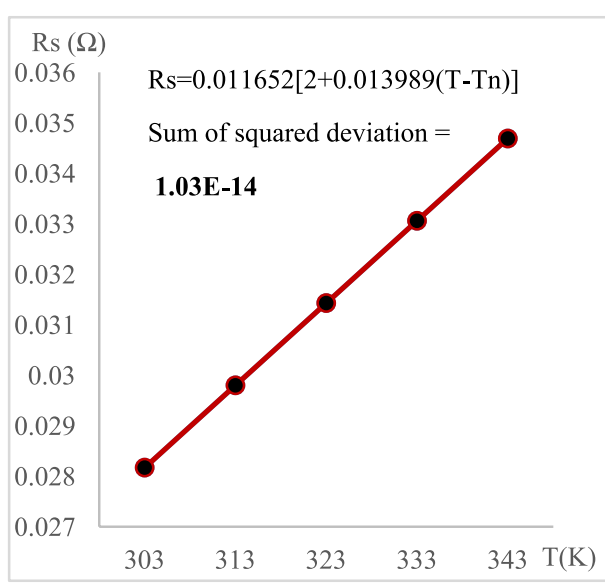

(a)

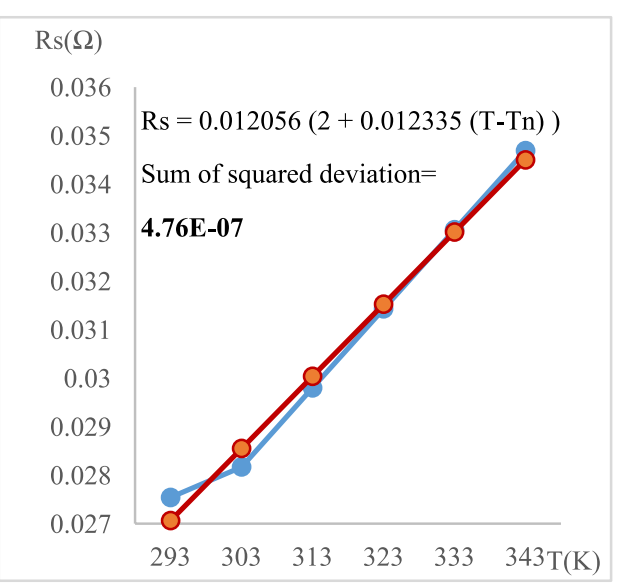

(b)

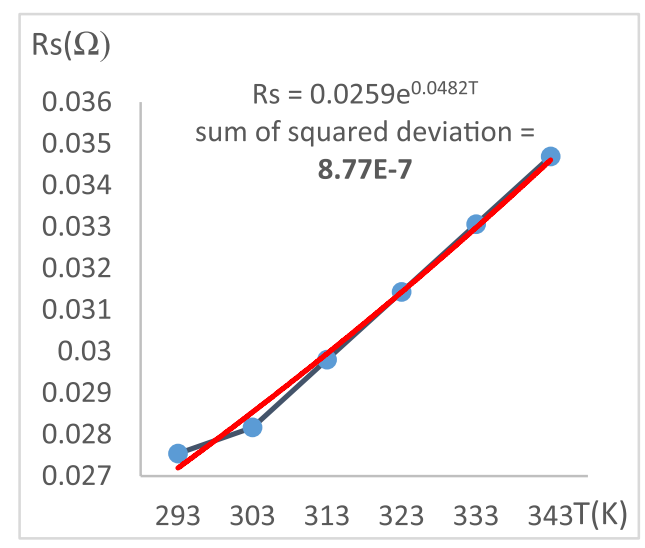

(c)

Fig. 3. Curve fitting and statistical analysis of the series resistance and temperature relationship (a) excluding the resistance values for temperature less than $25^{\circ} \mathrm{C}$ (b) Including the whole range of temperature (c) analysis for the model introduced by [8].

\section{Mathematical model}

Using KCL on the new model circuit shown in Fig. 1, the following equations can be obtained,

$$
I=I_{p v}-I_{d 1}-I_{d 2}-I_{R_{P}}
$$

$I_{p v}$ the light generated current, $I_{R_{P}}$ the current through the parallel resistance $R_{P}$, and $I_{d 1}$ and $I_{d 2}$ are the currents through diode 1 and diode 2, respectively, which are shown below,

$$
\begin{gathered}
I_{d 1}=I_{o 1}\left[\exp \left(\frac{V_{d}}{a_{1} V_{T}}\right)-1\right] \\
I_{d 2}=I_{o 2}\left[\exp \left(\frac{V_{d}}{a_{2} V_{T}}\right)-1\right] \\
I_{p v}=\left(I_{p v n}+K_{i} \Delta T\right) \frac{G}{G_{n}} \\
I_{p v n}=\frac{R_{s}+R_{p}}{R_{p}} I_{s c n}
\end{gathered}
$$


According to KVL, the voltage across the diodes is given by,

$$
V_{d}=V_{R d}+V_{R p}
$$

Knowing that $V_{R_{d}}$ and $V_{R_{p}}$ are the voltages across the resistances, $R_{d}$ and $R_{p}$ respectively. On the other hand, assuming that the value of $R_{d}$ is small and almost equal to $R_{s}\left(R_{d} \approx R_{S}\right)$,

$$
V_{d}=V+I\left(R_{d}+R_{S}\right)
$$

Since the value of $R_{d}$ is not fixed, then the voltage across the diodes can be given by:

$$
V_{d}=V+I\left(h * R_{S}\right)
$$

Where $R_{S}$ is the value of series resistance at STC, and for this work $h=d+$ $\propto\left(T-T_{n}\right)$, where $1 \leq d \leq 2$, then Eq. (2) becomes,

$$
\begin{aligned}
I= & I_{p v}-I_{o 1}\left[\exp \left(\frac{V+I\left(h R_{S}\right)}{a_{1} V_{T 1}}\right)-1\right]-I_{o 2}\left[\exp \left(\frac{V+I\left(h R_{S}\right)}{a_{2} V_{T 2}}\right)-1\right] \\
& -\left(\frac{V+I R_{S}}{R_{P}}\right)
\end{aligned}
$$

Equating the values of the calculated power and the experimental power at maximum power point $[9,10]$, the value of the parallel resistance can be calculated as follows,

$$
\begin{aligned}
& R_{p}= \\
& \left(\frac{V_{m}\left(V_{m}+I_{m} R_{s}\right)}{V_{m} I_{p v}-V_{m} I_{o 1} * \exp \left(\frac{V_{m}+I_{m}\left(h R_{s}\right)}{a_{1} V_{T}}\right)+V_{m} I_{o 1}-V_{m} I_{o 2} * \exp \left(\frac{V_{m}+I_{m}\left(h R_{s}\right)}{a_{2} V_{T}}\right)+V_{m} I_{o 2}-P_{m-e}}\right)
\end{aligned}
$$

To simplify the model, both the reverse saturation currents $I_{o 1}$ and $I_{o 2}$ are taken as equal in magnitude [10].

$$
I_{o 1}=I_{o 2}=I_{o}=\left(I_{p v}-V_{o c} / R_{p}\right) /\left(\exp \left(V_{o c} / V_{T}\right)-1\right)
$$

where $a_{1}=1$, and $1 \leq a_{2} \leq 2$ which implies that,

$$
I=I_{p v}-I_{o}\left[\exp \left(\frac{V+I\left(h R_{s}\right)}{V_{T}}\right)+\exp \left(\frac{V+I\left(h R_{s}\right)}{a_{2} V_{T}}\right)-2\right]-\frac{V+I R_{s}}{R_{p}}
$$

The initial conditions for the series and parallel resistances are given below,

$$
R_{s o}=0 ; \quad R_{p o}=\left(V_{m} /\left(I_{s c}-V_{m}\right)\right)-\left(\left(V_{o c}-V_{m}\right) / I_{m}\right)
$$

The value of the series resistance $R_{S}$ is increased gradually, in each iteration, and the corresponding value of the parallel resistance $R_{p}$ is calculated using Eq. (11). Alternatively, the values of the rest of the unknown parameters are calculated according to the resistances values, and the PV cells' output current can be calculated using Newton-Raphson method. Hence the number of unknown parameters are four parameters and the calculation is kept almost as simple as the single-diode model calculations.

\section{Results and discussion}

The new model is validated against single-diode model; the single-diode model with a series resistance $\left(R_{S}\right.$-model) only and the single-diode model with both 
series and a parallel resistance $\left(R_{P}\right.$-model); utilizing various $\mathrm{PV}$ modules from different manufacturers. For verification purpose five different PV modules (monocrystalline, multi-crystalline, and thin film) were used. The experimental data used to verify the model are collected from manufacturer datasheets and from $[4,9,10$, 11, 12]. The datasheet values for these modules under STC are shown in Table II.

The calculated parameters under STC, which are Series and shunt resistances $\left(R_{S}\right.$ and $\left.R_{P}\right)$, ideality factor $\left(a_{2}\right)$, reverse saturation current $\left(I_{o}\right)$, and the light generated current $\left(I_{p v}\right)$ are introduced for five different PV modules under STC. The extracted parameters with the use of the proposed two-diode model is shown in Table III, using the assumption that $I_{o 1}=I_{o 2}=I_{o}$ and $a_{1}=1$, where the number of parameters to be calculated remains almost the same as the single-diode model. Although the semiconductor resistance $R_{d}$ is much higher than the conductor resistance $R_{S}$, it is assumed in this work that $R_{d} \approx R_{S}$ at STC, which cancel the need for additional calculation for the new added resistance $R_{d}$.

Table II. Datasheet values for the modules used in validation (STC)

\begin{tabular}{|llllll|}
\hline $\begin{array}{l}\text { Datasheet } \\
\text { parameter }\end{array}$ & \multicolumn{2}{c}{ Multi-crystalline } & \multicolumn{2}{c|}{ Mono-crystalline } & Thin-film \\
\hline & $\begin{array}{l}\text { BP solar } \\
\text { MSX-60 }\end{array}$ & $\begin{array}{l}\text { Kyocera } \\
\text { KG200GT }\end{array}$ & $\begin{array}{l}\text { Shell } \\
\text { SQ150-PC }\end{array}$ & Shell SP-70 & Shell ST40 \\
& 3.8 & 8.21 & 4.8 & 4.7 & \\
\hline$I_{s c}(\mathrm{~A})$ & 21.1 & 32.9 & 43.4 & 21.4 & 2.68 \\
$V_{o c}(\mathrm{~V})$ & 3.5 & 7.61 & 4.4 & 4.25 & 23.3 \\
$I_{m}(\mathrm{~A})$ & 17.1 & 26.3 & 34 & 16.5 & 16.6 \\
$V_{m}(\mathrm{~V})$ & -80 & -123 & -161 & -76 & -100 \\
$K_{v}\left(\mathrm{mV} /{ }^{\circ} \mathrm{C}\right)$ & 3 & 3.18 & 1.4 & 2 & 0.35 \\
$K_{i}\left(\mathrm{~mA} /{ }^{\circ} \mathrm{C}\right)$ & 36 & 54 & 72 & 36 & 36 \\
$N_{s}$ & 36 & & & & \\
\hline
\end{tabular}

Table III. Parameters for the proposed two-diode model

\begin{tabular}{|lccccc|}
\hline \multirow{2}{*}{ parameter } & \multicolumn{2}{c}{ Multi-crystalline } & \multicolumn{2}{c|}{ Mono-crystalline } & \multirow{2}{*}{ Thin-film } \\
\cline { 2 - 5 } & BP solar & Kyocera & Shell & Shell SP-70 & Shell ST40 \\
& MSX-60 & KG200GT & SQ150-PC & & \\
\hline$I_{s c}(\mathrm{~A})$ & 3.80 & 8.2 & 4.8 & 4.701 & 2.680 \\
$V_{o c}(\mathrm{~V})$ & 21.1 & 32.9 & 43.4 & 21.40 & 23.300 \\
$I_{m}(\mathrm{~A})$ & 3.49 & 7.609 & 4.398 & 4.255 & 2.401 \\
$V_{m}(\mathrm{~V})$ & 17.10 & 26.3 & 34.008 & 16.478 & 16.659 \\
$I_{o l}=I_{o l}(\mathrm{~A})$ & $4.55 \mathrm{e}-10$ & $4.025 \mathrm{e}-10$ & $2.997 \mathrm{e}-10$ & $3.977 \mathrm{e}-010$ & $2.923 \mathrm{e}-011$ \\
$I_{p v}(\mathrm{~A})$ & 3.80 & 8.20 & 4.80 & 4.71 & 2.69 \\
$a_{2}$ & 1.3 & 1.5 & 1.4 & 1.3 & 1.2 \\
$R_{S}(\Omega)$ & 0.184 & 0.168 & 0.465 & 0.27 & 0.864 \\
$R_{d}(\Omega)$ & 0.184 & 0.168 & 0.465 & 0.27 & 0.864 \\
$R_{p}(\Omega)$ & 154.36 & 168.602 & 247.64 & 89.487 & 160.613 \\
\hline
\end{tabular}

Fig. 4(a, b) shows the I-V curves of the proposed two-diode model against the experimental data of two different PV modules, MSX60 and Q6LM, under STC. The red circles and red squares in Fig. $4 \mathrm{a}$ and Fig. $4 \mathrm{~b}$ respectively, represent the experimental values, while the black line represents the values calculated using the 
proposed two-diode model. From Fig. 4, it can be noticeably seen that the proposed model matches the experimental data accurately, for both modules.

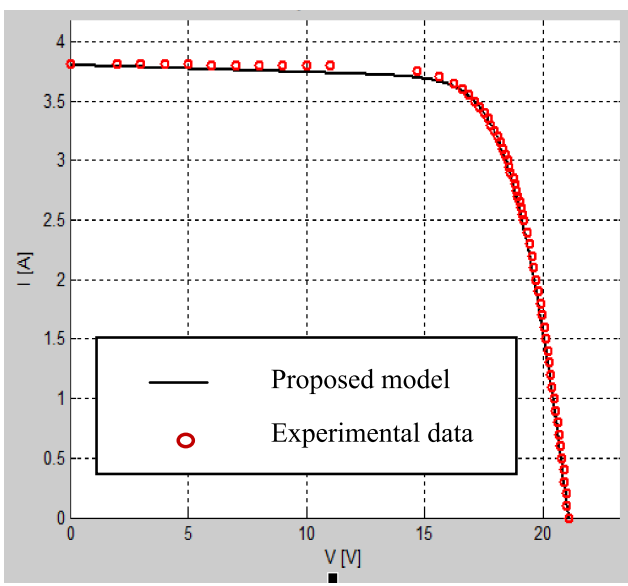

(a)

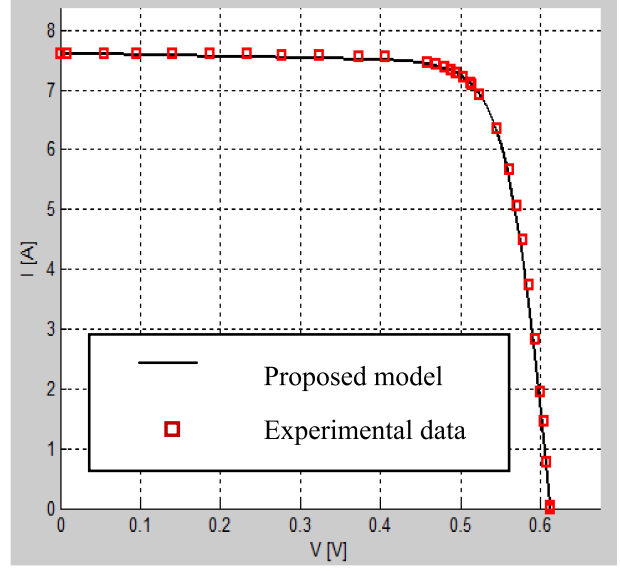

(b)

Fig. 4. Experimental against calculated $\mathrm{I}-\mathrm{V}$ values using the proposed two-model under STC (a) MSX60 multi-crystalline PV module (b) Q6LM PV module

Fig. 5 shows the simulated I-V curves utilizing the proposed model for the Solarex MSX60 solar panel, at four different temperature levels, against the experimental data and the simulated data using $R_{P}$-model [1] and $R_{S}$-model. It can be noticed that the proposed model matches the experimental data precisely compared to the other two models.

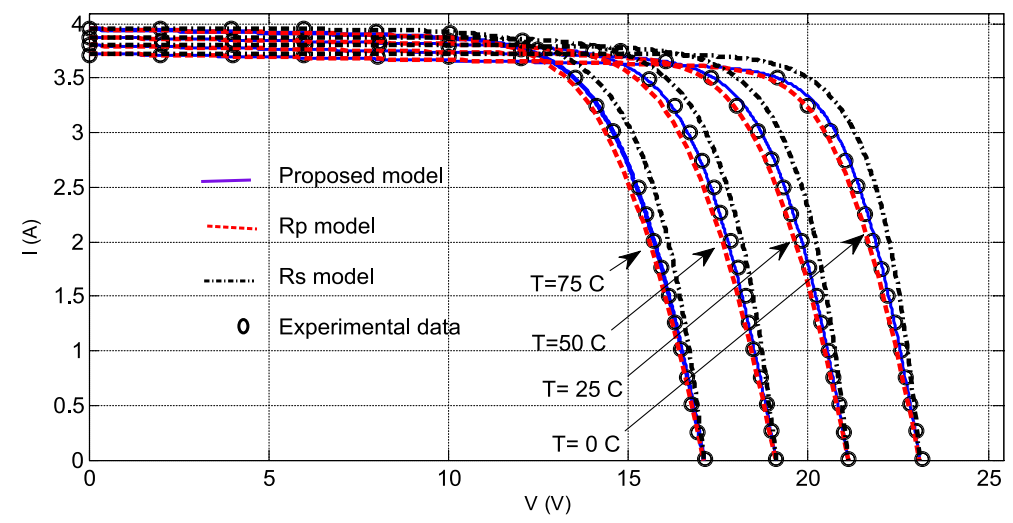

Fig. 5. I-V curves of MSX60 PV module experimental data against all of the RS-model, RP-model and the proposed model, for different temperature levels

In addition, the absolute error of the proposed model with respect to the experimental data is shown in Fig. 6 . The proposed model is compared with $R_{P^{-}}$ model, as they are plotted on the same graph, showing the superiority of our model, especially at the vicinity of the maximum point. 


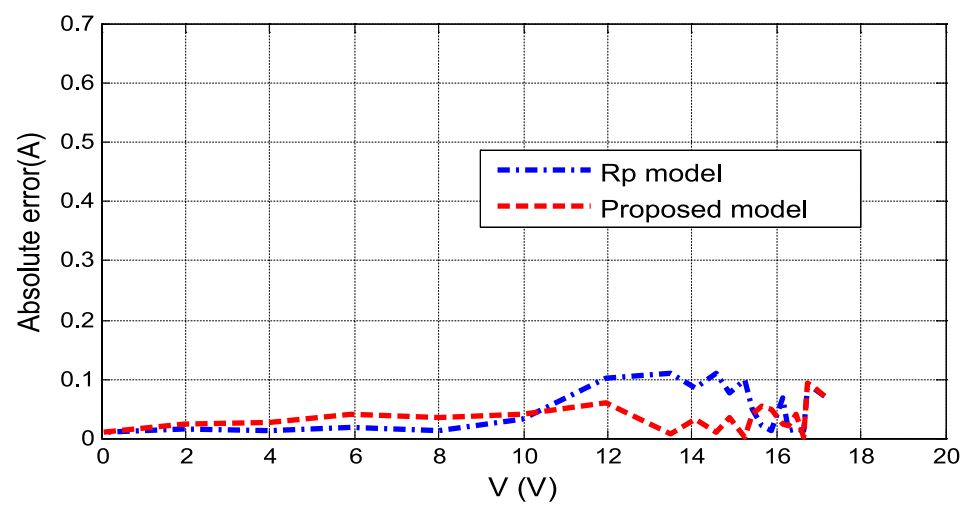

Fig. 6. Absolute errors of the proposed model and the model in [1] for solarex MSX60 solar array at $75^{\circ} \mathrm{C}, 1000 \mathrm{~W} / \mathrm{m}^{2}$.

\section{Conclusion}

This paper study the physical properties of the main parts which form the series resistance in the two-diode model of the PV module, with respect to temperature variation. A new two diode-model was proposed with its mathematical model, which is capable of fitting the I-V curve of the PV module precisely, especially at the maximum point for the voltage and current. Different PV modules are used to validate the proposed model, in which it shows a satisfactory accuracy versus the single-diode model. It is found that the new-model is accurate when subjected to temperature variations. The proposed model presents a great aid to the PV module designers.

\section{Aknowledgment}

The authors wish to acknowledge the support provided by Universiti Teknologi PETRONAS, Malaysia to complete this work successfully. 